\title{
Research on the Innovation of Convergent Courses in Practical Teaching in the Costume and Fashion Specialty of Newly-Established Colleges and Universities
}

\author{
Yi Zhang \\ City College, Wuhan University of Science and Technology, Wuhan, Hubei, China
}

Keywords: convergent courses; practice-centered teaching model; newly-established universities

\begin{abstract}
Costume and Fashion specialties belong to the design category, which is featured with a certain aesthetic foundation and strong practicality. Therefore, the establishment of a practice-centered teaching system plays a pivotal role in the Costume and Fashion specialties. In order to innovate the practice-oriented teaching system, highlight the characteristics of the newly-built undergraduate colleges and universities, and cultivate comprehensive talents to fully enhance the professional quality of students, it is necessary to reform the existing teaching model. This paper analyzes the status and existing problems of the costume and fashion design profession in newly-built undergraduate colleges and universities, and then discusses how to construct an effective new practice-centered teaching model.
\end{abstract}

\section{Introduction}

With the rapid development of our society and economy, the traditional teacher-centered teaching model must be reformed. Costume and fashion specialty is a professional with strong practicality. In addition to requiring students to have a certain aesthetic ability, it also requires students to have a strong hands-on ability, the understanding of the clothing structure, as well as the ability to innovate. Therefore, the talent training mode and curriculum system of the clothing and apparel industry need continuous reform and innovation. The ultimate goal of teaching is to cultivate excellent design talents who adapt to society. Therefore, in the practice-centered teaching process, it is very important to cultivate students' comprehensive ability.

How to construct a new practice-centered teaching system is an important issue for the educators in the current costume and fashion specialty in undergraduate colleges. This article starts with the current problems and status of the costume and fashion specialty in newly-built undergraduate colleges, analyzing them, and then discussing how to construct a practice-centered teaching and conduct research on integrated courses.

\section{Status of Teaching Costume and Fashion Specialty in Newly-built Colleges and Universites}

In China's new undergraduate colleges (hereinafter referred to as NU), the establishment of the costume and fashion specialty is relatively late. Most of its teaching methods and training programs are based on the experience and mode of undergraduate teaching of first-class domestic universities. There is basically no school-running feature and no specific training for professional talents in NU. The integration with the market often fails to find a suitable point of convergence. Graduates from NU and graduates from first-class colleges and universities compete for the same jobs in the job search process. Therefore, the NU should be more targeted in the training program, find a training mode that is more suitable for the students themselves, and be able to find the market's meeting point, so as to distinguish it from the domestic first-rate institutions, so that the talents can be qualified for the needs of the apparel market Output. 


\section{Practice-centered Integrated Curriculum Teaching in the Costume and Fashion Specialty of Newly-built Undergraduate Colleges and Universities}

\subsection{Professional curriculum model under the guidance of internet thinking}

With the rapid development of science and technology, the Internet plus has become a new model, and it has comprehensively and profoundly influenced all aspects of people's lives. In this background, the teaching of clothing and apparel is also facing a transformation. Therefore, how to use Internet thinking to carry out teaching reforms and innovations in the costume and fashion specialty; how to cultivate talents adapted to social development has become the focus of social concern.

\subsection{Internet platform for the professional teaching of costume and fashion specialty}

Costume design is a comprehensive discipline with many disciplines including design, aesthetics, psychology, and materials science. Due to its unique professional nature, it requires a lot of up-to-date information, screening and sharing of resources so as to effectively improve teaching efficiency. Teachers can make full use of network resources, combine network resources with traditional teaching, and find out a new type of teaching model that suits their characteristics.

\subsection{Teaching innovation of costume and fashion specialty in the Internet age}

In practical teaching, through an in-depth investigation and research on the apparel industry, and on the basis of further research on the development of the Internet, an integrated teaching model of "Internet + project + market" was established, focusing on cultivating students to use the Internet to learn and practice the comprehensive ability. Specifically include the following: First, the training of the Internet, smart mobile terminal related operating skills. Second, develop the ability to develop networked products. Third, train students to be able to collect information on the Internet, and to screen and analyze this, to grasp the market's trends and customer needs. Fourth, develop students' ability to operate independently online and offline.

\subsection{Enhance the internationalization of costume and fashion specialty teaching in the internet era}

Fashion design is a professional closely linked with the international community. Teachers in the practical classroom make full use of the Internet to obtain information, so that the classroom content is at the forefront of the popular. The purposeful research and development of virtual network teaching experiment software based on network technology can greatly improve the teaching quality and teaching level of the clothing specialty, and it also has far-reaching significance for the comprehensive training of students' professional qualities.

The internationalized teaching should also establish a good atmosphere of direct mutual promotion and mutual exchange among universities, regions, and countries. At the same time, fully taking into account the use of the latest science and technology to assist teaching, using the most cutting-edge clothing materials as a support, so as to achieve teaching interaction, the most advanced international consulting through the most effective way to teach students to achieve common progress.

\section{The New Model of Professional Course Teaching Based on Project}

\subsection{Project integration into teachers' teaching program}

The costume and fashion specialty is a professional that is closely integrated with the company and has strong practicality on the basis of theoretical knowledge. Therefore, when teachers prepare teaching plans, they can put their own teaching and research, scientific research projects in the curriculum of the teaching plan. Due to different professional courses, the module settings for teaching are also different, making the teaching with distinctive curriculum characteristics. The fashion design profession is based on the current production category and job requirements of 
fashion companies, and special ability modules such as apparel design, apparel buyer, garment making, garment display, and apparel marketing are concomitantly opened. Therefore, when teachers apply for the project and teaching plan, they should constantly improve their own teaching design in response to changes in the market, and form a project-oriented modular curriculum system.

According to a professionally-designed, project-oriented modular curriculum system, a practice-centered, integrated curriculum is implemented. Each unit's teaching module should be designed to develop an operable teaching plan. Bring real projects into teaching, emphasizing “Teach in Learning”, "Learning to Do", applying such Trinity teaching concept. The teacher will decompose the teaching project of the company into practical courses, and the students will achieve the teaching goal in the process of completing the production project task. The work tasks and teaching tasks cooperate with each other, fully embodying the characteristics of industry-university integration in personnel training.

The multiple forms of assessment organized by the teachers and the base technicians are jointly implemented by the school and enterprises. This form of teaching can reflect flexible, diverse and novel features. Through campus multi-media teaching, off-campus market research, teamwork form to complete the production, and communicate with the company throughout the entire process, and finally to test results according to company's standards, so that students truly understand the market mechanism and business model. In this type of teaching, teacher's curriculum can also be updated in time, avoiding the disadvantages of repeating content to students every year.

\subsection{Quality monitoring of project integration course}

In order to cultivate students who meet the requirements of the company and society, it is necessary to effectively monitor and manage the entire process. In the strict process of teaching management, we will gradually establish and improve the project-oriented modular teaching quality standards: the selection of projects, the determination of project tasks, preparation of lessons, lectures, internships, assessments, and the results submitted and all these assessments require the development of corresponding quality standards. Students in the company's implementation of the teaching process, mainly relying on the business monitoring and evaluation; in the school, the supervision by the teacher and the Department of Education; at the same time, the supervision of the teaching process of the enterprise. This can ensure project-oriented modular teaching, it has better quality control and timely improvement to ensure the quality of personnel training. We can also find gaps through information collection and analysis to meet the needs of evolving businesses and society.

The project-oriented modular curriculum is highly professional, open, and practical. Such a curriculum system overcomes the drawbacks of the original one, conforms to the teaching philosophy and characteristics of the newly-established undergraduate colleges, and adapts to the requirements for the training of professional personnel in clothing and apparel design, and can better train application-oriented talents for market positions.

\subsection{Small-scale teaching forms that bring studios into the classroom}

With the constant innovation and development of garment technology, garment companies need more integrated design talents with both innovative and practical skills. This requires us to build a composite based on theoretical knowledge and practical skills to support and create compound talents full of competence. In this situation, the clothing studio's small-volume custom clothing just caters to this need. In the studio can also cultivate students' ability to use knowledge comprehensively.

The studio's teaching style is based on learning and adopts the teaching styles of passing, helping, and taking. Combining the actual conditions of the industry and enterprises, fashion trends, and advanced technologies, it not only cultivates students' comprehensive ability in production, learning, and research, but also trains students. Innovative design and practical ability. The combination of teaching and small-scale studios in the industry also helps students understand the market in many 
aspects and improve their ability to analyze problems and solve problems independently.

\subsection{Convergence}

The studio teaching is a comprehensive practical teaching mode in which garment design, garment making, garment craftsmanship, clothing uniforms, and clothing display are integrated. Through the production of a complete set of processes in the studio, students can grasp the entire system from data analysis to product development and garment production and product tracking. Students can communicate with their teachers at any time during the learning process, solve problems in a timely manner, and improve the efficiency of learning. They can study problems independently and can master the connections among various disciplines. Therefore, it is a very good comprehensive teaching model.

\subsection{Freedom}

The teaching style of the studio has the characteristics that the development direction can be freely chosen and the teaching method is flexible. The students complete the practice part of the costume design course under the guidance of the instructor. Students learn the theoretical knowledge and use it, not only to train students in the sense of teamwork, but also to adjust the monotonous teaching mode between teachers and students.

\subsection{Diversity}

The implementation of studio teaching forms allows students to experience the comprehensive application of knowledge in practice. In this teaching mode, teaching is not affected by the form, teaching emphasizes the combination of product design and product development needs, focuses on the cultivation and expression of innovative thinking, and strengthens the training of practical skills.

\subsection{Collaboration}

The teaching projects in the studio are organized in small groups, focusing on the potential of students' creative thinking and cultivating the teamwork of students. In the course of teaching, the project's planning, analysis, and the division of labor in all aspects are clear and inspiring, so they can be very good at training students' ability to cooperate with each other. Only in this way can the overall team's capabilities be maximized. Through this type of study and exercise, the students' cooperative spirit can be well trained.

\subsection{Bringing professional skills contest into the teaching mode of professional courses}

The Fashion Design Competition is a platform for the exchange of clothing professionals, and it is also a way for young professionals to grow rapidly. Contests can not only bring good opportunities for professional talents, but also a positive challenge for professionals. In the teaching of targeted introduction of some events, in the course of effective design, to achieve the perfect combination of theory and practice.

With the continuous development of society, the continuous opening up of teaching forms, the continuous integration of teaching content, there are the increasingly demands for combination of students' hands-on capabilities and innovative capabilities. The clothing competition is the incubation place for the development of practical and innovative talents. The development of skills competitions among students can fully mobilize the enthusiasm and initiative of students in learning so as to improve students' comprehensive ability. It also highlights the importance of practical teaching and points out a new direction for practical teaching of clothing and apparel.

The integration of design competition and clothing teaching plays an important role in stimulating students' enthusiasm for learning, improving the overall quality of teachers, strengthening the teaching of practical skills, and improving the quality of teaching. In the concept of practical teaching, we should advocate "to promote learning through competition, to promote practice through competition, promote competition through competition, promote reform through competition, and promote construction through competition." Explore new modes, new methods, and new systems that integrate the competition with normal teaching. In the process of research and 
discussion, a new situation in which students' practical skills, teachers' teaching standards and school teaching quality are jointly promoted.

\section{Summary}

In short, the study of practical teaching mode is a directional, overall, and developmental work. It is a systematic project. Under the new industry pattern, the training of talents should continue to adapt to changes in new talent requirements, further improve the new model of practical teaching reform, promote the development and innovation of new undergraduate colleges, improve the quality of talent output, and cultivate comprehensive technical talents fitting an overall development strategy for the country and needed for economic development.

\section{References}

[1] Zhi Huiyun. Teaching discussion on "Fusion of Production and Education" in Costume Specialty [J]. Education and Teaching Forum, 2015, 50: 233 234

[2] Xu Qiang. Constructing a professional course system based on practical innovation[J]. Textile and Clothing Education, 2017, 3: 226 229

[3] Sun Yanyan. Innovation and Practice of Innovative Talent Cultivation Mode in Textile and Apparel[J]. Textile Education, 2018, 2: 66 72

[4] SUN Siyang. Teaching Research on Introducing Workshop Mode into Fashion Technology Course[J]. Shandong Textile Economy,2016,2

[5] Guo Lipeng. Reflections on the Reform of Clothing Specialty Courses in Technical Colleges [J]. Science and Technology World, 2015, 35

[6] Liu Chenjiao. Exploration of college students' innovation and entrepreneurship in the era of Internet $+[\mathrm{J}]$. Teaching in the Forest District, 2016, 2: 107 109

[7] $\mathrm{Hu}$ Wenlong. Research on Engineering Based on CDIO[J]. Research in Higher Education of Engineering, 2014, 1:163 168

[8] Qin Lina. Considerations on the reform of costume design teaching in higher vocational colleges [J]. Modern Enterprise Education, 2010, 8:35 